\title{
The marginalized knowledge: An informetric analysis of indigenous knowledge publications (1990-2004)
}

\author{
Dennis N. Ocholla' and Omwoyo Bosire Onyancha ${ }^{2}$ \\ Department of Library and Information Science, University of Zululand, XI00I, \\ KwaDlangezwa 3886, South Africa \\ docholla@pan.uzulu.ac.za,b_Onyancha@yahoo.com
}

Received: $15^{\text {th }}$ August 2005

Accepted: $5^{\text {th }}$ October 2005

\begin{abstract}
The paper analyses and demonstrates the application of informetrics by use of descriptive bibliometrics to determine the status and trend of Indigenous Knowledge (IK) development from 1990 -2002. IK records published during that period have been analyzed by use of eight databases hosted by EBSCOHost and SABINET by document type, by growth of the literature over the period, by source where the document is published, by document affiliation, by subject domain, and by nature of authorship among others. A positive growth of IK is observed with strong representation in AGRICOLA database and recommendations are given for a follow up and further research. It is recognized that the paper could provide useful information for decision support in knowledge management in general and knowledge management in particular.
\end{abstract}

Key Words: Knowledge Management; Indigenous Knowledge; Informetrics

\section{Background and purpose of the study}

Indigenous knowledge systems and management is receiving significant World attention as witnessed in a recent paper on Tapping Indigenous Knowledge (IK) on the World Wide Web (Le Roux 2003). Strong African studies that give IK visibility and attention are growing as attested at the SCECSAL conference 2002 that was fully dedicated to IK research and information(see $h t t p: / / w w w . d i s s a n e t . c o m)$. We have also witnessed the creation and growth of Indilinga-African Journal of Indigenous Knowledge System (see: http://indilinga.org.za) based in South Africa that focuses on the promotion of IK research and IK information exchange and preservation largely in Africa. Indigenous knowledge can be defined (e.g. NRF, n.d.) as "complex set of knowledge and technologies existing and developed around specific conditions of populations and communities indigenous to a particular geographic area" with an emphasis that "these forms of knowledge have hitherto been suppressed ... therefore, IKS should be brought into the mainstream of knowledge in order to establish its place within the larger body of knowledge". Indigenous knowledge is, thus, a dynamic archive of the sum total of knowledge, skills and attitudes belonging to a community over generations and expressed in form of action, object and sign languages for sharing. These skills, knowledge and attitudes are shared, adapted and refined and therefore change with time.

The popularization of knowledge management since mid 90's has generated debates on the concept and reconsideration of KM conceptions and components. For example, Skyme (1995) views KM to be the explicit and systematic management of necessary knowledge and the accompanying processes of creating, gathering, unlocking and developing this knowledge. Todd in Mosia and Ngulube (2005:176) defines KM more explicitly, thus, "it is a process of organizing and leveraging knowledge embedded in people's experiences, competencies, talents, ideas, practices, intuitions, skills, wisdom and capabilities, in addition to documented and codified sources" One of the fundamental focus areas of KM, we believe, is the conversion of intangible knowledge (e.g. indigenous knowledge -IK) to tangible knowledge. Nonaka and Takeuchi (1995:62) define intangible knowledge as personal knowledge resulting from individual experiences. This knowledge is largely embedded in the culture and tradition of individuals or communities. Tangible knowledge is recorded, documented or codified knowledge that is widely conveyed in formal language such as textual, electronic or digital. The form of representation of this kind of knowledge has made its storage, conveyance and sharing extremely easy and its popularization overwhelming. However, notes Nonaka and Takeuchi (1998:8), tangible and intangible knowledge are not two separate entities: they supplement one another. Knowledge, in the two authors view, is created and extended by the social interaction between tangible and intangible knowledge, and may be represented in four basic patterns:

- Intangible to intangible: socializing - where individuals share intangible knowledge during personal contact.

- Intangible to tangible: externalization - where the knowledge base is extended by the codification of experience,

I. Dennis N. Ocholla is professor and Head of the Department of Library and Information Science, University of Zululand, South Africa

2. Omwoyo Bosire Onyancha is a PhD student in the Department of Library and Information Science, University of Zululand, South Africa and Assistant Librarian University of Eastern Africa, Baraton, Kenya. 
insight and judgment so that it may also be utilized by others.

- From tangible to tangible: combination - where individuals combine the tangible knowledge of others to form a new whole.

- Tangible to intangible: internalization - where individuals use the codified knowledge of others to broaden their own intangible knowledge.

\begin{tabular}{|c|c|c|}
\hline $\begin{array}{l}\text { TO } \\
\text { FROM }\end{array}$ & Tacit & Explicit \\
\hline Tacit & Socialization & Externj zation \\
\hline Explicit & Internalization & Combination \\
\hline
\end{tabular}

Figure 1 Four modes of knowledge conversion (Source: Nonaka \& Takeuchi, 1995:62)

Evidently, indigenous knowledge that is popularly associated with tacit or intangible knowledge is inseparable from any realistic knowledge management paradigm. Unfortunately, for reasons largely associated with ignorance and arrogance, IK has been neglected, vindicated, stigmatized, illegalized and suppressed among majority of the world communities. Perhaps the understanding that tangible knowledge and intangible knowledge are not separate things was not understood or simply ignored.

Encouragingly, indigenous knowledge has been brought back to fore because of interventions by governments and civil societies and communities through for example, legislation and policies e.g. intellectual property rights, research, popularization and benefits in such areas as alternative medicine, nutrition or sports and business. There has been increasing fear of globalization that increasingly melts down traditions and cultures as well.

It is recognized through the development and growth of bibliometrics (e.g. Hertzel 1987; Sengupta 1992; Hood and Wilson 200I; Ikpaahindi 1985; Rousseau 2002; Wormell 200I) that infometrics could be employed for the quantitative analysis or measurement of all forms of recorded knowledge and information in pure, applied and action research (Twining, 200I) and social sciences and humanities (Archambault \& Gagne, 2004; Ungern-Sternberg, 1995) including indigenous knowledge. The purpose of this paper is to demonstrate the effectiveness of informetrics for the determina tion of the development of Indigenous Knowledge (IK) by analyzing records indexed in selected EBSCO and South African Bibliographic Network (SABINET) databases from 1990-2004 that reflect both international and South African publication trends.

\section{Informetrics}

The terms informetrics, bibliometrics, scientometrics can be used interchangeably. For example, Hood and Wilson (200I), Wormel (200I) and Sengupta (1992) among others confess that it is difficult to distinguish bibliometrics, scientometrics and informetrics although the metrics are not necessarily similar. It is believed that both informetrics and bibliometrics study the distribution, circulation and use pattern of publications by use of statistical methods. Twining (200I) adds that informetrics focuses on patterns of the data information-knowledge transfer process. A large part of the broader definition is shared with, for example, scientometrics - methodologies that apply quantitative mathematical studies to science and technology (Spiegel-Rosing in Diodato, 1994:146), webometrics - the study of the quantitative aspects of the construction and use of information resources, structures and technologies on the Web (Björneborn \& Ingwersen, 2004:1217), cybermetrics - the study of the quantitative aspects of the construction and use of information resources, structures and technologies on the whole Internet (Björneborn in Björneborn \& Ingwersen, 2004:1217) and citation analysis - the practices and patterns of scholarly referencing as shown in Fig. 2. 


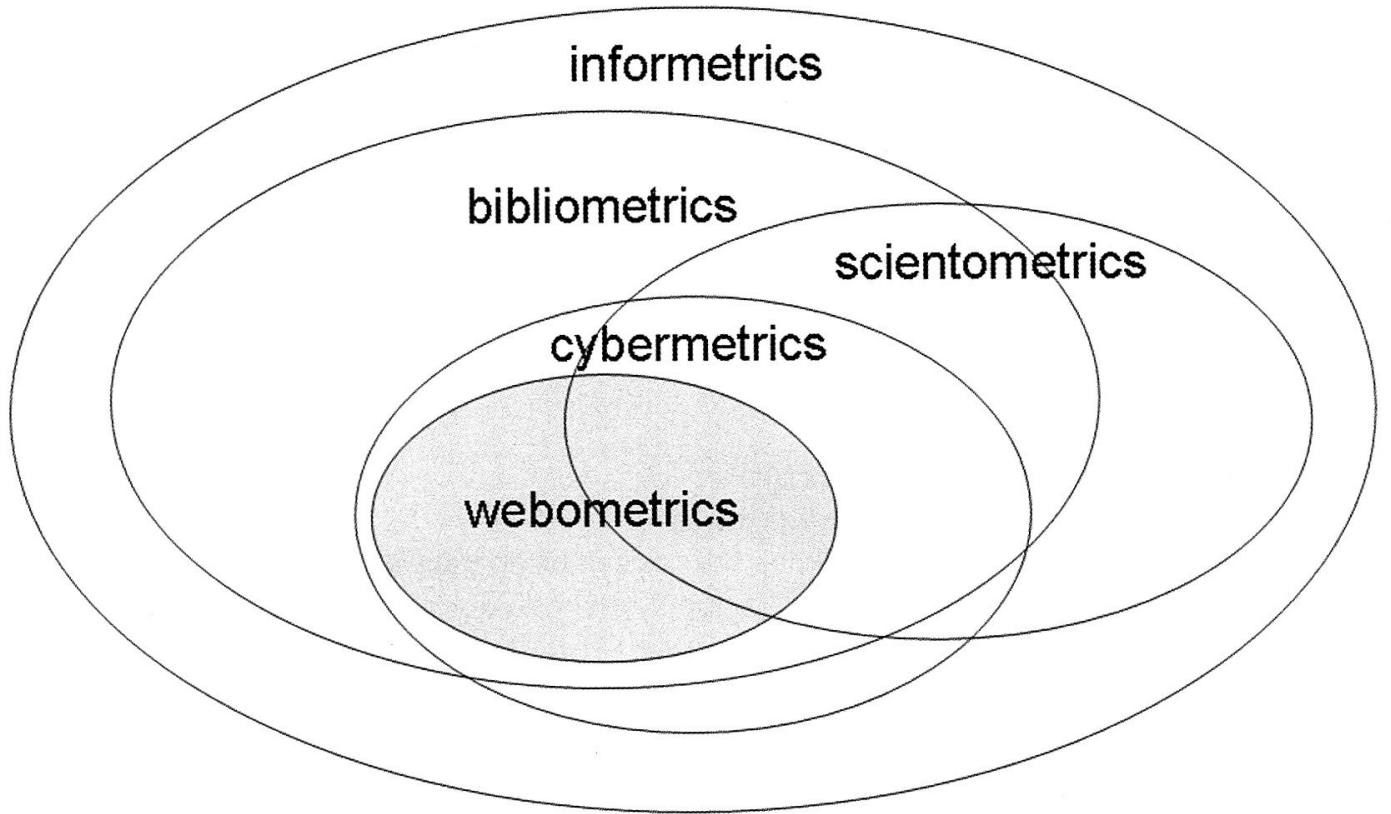

Figure 2 The sizes of the overlapping between Informetrics, bibliometrics, scientometrics, cybermetrics and Webometrics (Source: Björneborn \& Ingwersen, 2004).

Observably, informetrics and other related metrics utilize quantitative analysis, statistics, and data visualization (i.e. dimensional mapping) to investigate and represent the patterns in the data-information-knowledge transfer process, at the procedural, contextual, and conceptual levels and within relationships among user, media, and message (meaning). Informetrics include (but is not limited to) analysis of publication and transfer patterns within a given field, for instance, a body of literature, an organization, an environment or enterprise, and within and between disciplines. Informetrics is applied to develop and measure information and knowledge transfer in traditional (print-based) as well as proprietary electronic information environments (databases and databanks). It is the foundation for much of the technological advancement of the emerging Internet, and, increasingly, is used for the development of human-based knowledge systems. Informetrics is an established knowledge domain unique to LIS and incorporates its own set of laws and theories, its own methodologies, its own technologies, and its own specialized journals, conferences, and associations (http:// apollo.iwt.uni-bielefeld.de/mw/bibliometrics/).

Historically, it is noted by Hood \& Wilson (200I), Ocholla (2000), Rousseau (2002), Sengupta (1992), and Victoria (n.d.), among others, that informetrics has some prototypes in the $19^{\text {th }}$ century. Its growth in the $20^{\text {th }}$ Century is associated with contributions by Cole and Eales in 1917, Wyndram Hulme in 1923 who also mooted the term 'statistical bibliography' for the first time and SR Ranganathan in 1948, who first mentioned the term 'librametrics' denoting the quantification of usage patterns of library materials and user activities in libraries. Since 1940 informetrics has flourished and has become a major sub-discipline within information science, and has attracted large-scale research such as that being spearheaded by the Institute of Scientific Information (ISI) - now Thomson Scientific - in Philadelphia USA. More recently, it has formed into a membership club, the International Society for Scientometrics and Infometrics' (ISSI) to develop and spearhead research, scholarly exchange and dissemination of bibliometrics, scientometrics and informetrics information. ISSI meets regularly bi-annually. For example, the latest ISSI conference took place in Stockholm, Sweden, from $24^{\text {th }}$ to $28^{\text {th }}$ July 2005. An informative highlight of the historical development of bibliometrics/informetrics/ scientometrics/webometrics and other metrics between $1913-1990$ also termed as 'Time Line of Bibliometrics' is provided by Rousseau (2002) and Hertzel (1987:I54-I55) as well as ISI (http://www.isinet.com/isi/about/timeline.html).

The popularization of infometrics, we believe, is orchestrated by its wide uses. For example, Twining (200I) observes that, in pure/basic research it is used to map knowledge structures to determine such things as the level and nature of collaboration between scientists and disciplines; technology transfer; disciplinary encroachment, interdisciplinarity, and other geographic boundary flows; and knowledge drift and migration. In applied research it can be used for thesaurus construction; taxonomy and ontology development; metadata development; design of metric-based management, product, technology, and communication integration systems; to relate cause and effect, such as patent citation metrics as a measure of transfer of technology from science to industry, and for policy and decision support while in action research, informetrics techniques are used for design and execution of knowledge and community flow designs; and evaluation 
studies for research funding and training programs (Twining, 200I). As far as LIS is concerned, Morales (in Sengupta, 1992) views the method as an integral part of information science. Among the potential areas where informetric studies thus can be used with profitable results include (Sengupta, 1992:84):

- Quantitative growth of literature;

- Obsolescence and scattering of information;

- Efficiency in information products and services in science and technology and production;

- Efficiency of the information system and information establishment in general;

- The role of different kinds of documents as a means of scientific communication;

- Information pertinence and relevance;

- Ranking of periodicals and serials by various parameters;

- The role of informal channels in scientific communication;

- Overlapping of subject contents between periodicals and serials;

- Citation habits of scientists and the growing role of citation analysis' and

- Intradisciplinary and interdisciplinary relations as determined on the basis of bibliographical references.

Primarily, it is widely acknowledged that informetrics is a decision-support methodology applicable to many disciplines and used by Library and Information Science and Knowledge Management professionals in and across virtually every discipline, be it in pure, applied science or humanities and social sciences. Informetrics is rich with methods, which includes some of the following:

- Citation analysis focusing on relationships between authors or their work, between journals, between fields, between countries;

- Co-citation analysis that establishes a subject similarity or relationship between two documents (Ikipaahindi, 1985; Marshakova, 1973; Small, 1973; Ungern-Sternberg, 1995);

- Bibliographic coupling that focuses on the links between papers that cite the same articles (Fano, 1956 and Kessler, 1963 in Ikpaahindi, 1985);

- Co-word analysis focusing on the co-occurrence of keywords (Polanco, 1995 and Ungern-Sternberg, 1995);

- Webmetrics/cybermetrics that studies the relationship of sites on the Web (Björneborn \& Ingwersen, 2004);

- Impact factor that determines the ratio between the citation rate of the journal and its potential through citation analysis of publication, in top ISI, peer refereed journals (Garfield I 979 in Ikpaahindi, I 985: 166)

Some of the bibliometric laws that may be applied in IK include Bradford's Law of Core and Scatter in Journals, Lokta's Law of Scientific Productivity of Authors and Zipf's law of human behavior and the principle of least effort.

\section{Methodology}

Notwithstanding limitations of descriptive informetrics some of which are expressed by Lewison (2002), Pichappan and Sarasvady (2002) we have recognized its popularity (see Onyancha and Ocholla 2004; Ocholla, 2000) and used the method to analyze and to determine IK by document type, by eight databases hosted by EBSCO and SABINET, by growth of the literature over a period of 15 years, by source where the document is published, by document affiliation, by subject domain, and by nature of authorship. A Boolean search by use of two broad terms, thus "Indigenous Knowledge" (IK) OR "Traditional Knowledge" (TK) was conducted on the selected databases. Six of the eleven EBSCO Host- databases were purposively selected for analysis. They included:

- Firstly, Academic Search Premier (ASP), a multi-disciplinary database that provides full text for over 4,000 scholarly publications that includes over 3,100 peer-reviewed journals;

- Secondly, AGRICOLA (AGRICultural OnLine Access), a bibliographic database of citations to the agricultural literature created by the National Agricultural Library (NAL) and its co-operators. The records describe publications and resources encompassing all aspects of agriculture and allied disciplines, including animal and veterinary sciences, entomology, plant sciences, forestry, aquaculture and fisheries, farming and farming systems, agricultural economics, extension and education, food and human nutrition, and earth and environmental sciences. The database includes journal articles, book chapters, short reports, and reprints.

- Thirdly, Business Source Premier (BSP), the largest full text business database providing nearly 3,300 scholarly business journals that includes full texts for more than 1000 peer-reviewed journals;

- Fourthly, ERIC that focuses on education resources/records consisting of 2,200 digest and 980 educational journals;

- Fifthly, Master File Premier (MFP) that covers subjects of general interest by providing full texts to nearly 2000 general publications; and

- Finally, MEDLINE, that allows users to search from over 4600 journals on such subjects as medicine, nursing, dentistry, veterinary medicine, the health care system, pre-clinical sciences, and much more.

In addition to the aforementioned EBSCO Host databases, relevant records were downloaded from two SABINET (South African Bibliographic Network) databases, namely, the Index of South African Periodicals (ISAP) and the Current and Completed Research (C\&CR) for the same period in order to determine the South African indigenous knowledge research/publication pattern and output. Data were captured, merged and stored in Excel spreadsheets and analyzed by 
the categories highlighted. Microsoft Excel and Bibexcel were largely used to process and represent the quantitative data and obtain frequencies upon the removal of duplicates, respectively.

\section{Results and Discussions}

This section provides an analysis of IK records as reflected in the eight databases under eight headings. Distribution of records by database, distribution of documents by document type, distribution of IK records by database and year of publication, growth of indigenous knowledge literature from 1990 to 2004,distribution of documents by source, distribution of IK publications by document affiliation, subject representation of IK literature and nature of authorship

4.1 Distribution of documents by database

The distribution of the total number of relevant records downloaded is as shown in Table I. AGRICOLA database produced most of the documents (i.e. 430 or $23.8 \%$ ) followed by EBSCO-ASP (383 or $21.2 \%$ ) and at the bottom of the Table is EBSCO-BSP, which yielded 56 records, accounting for $3.1 \%$. Seemingly, indigenous knowledge is mostly used in agriculture and its allied disciplines, such as animal and veterinary sciences, entomology, plant sciences, forestry, aquaculture and fisheries, farming and farming systems, agricultural economics, extension and education, food and human nutrition, and earth and environmental sciences.

Table I Distribution by database $(\mathrm{N}=1808)$

\begin{tabular}{clcc}
\hline Rank & \multicolumn{1}{c}{ Database } & Number of Records & Percent \\
\hline 1 & AGRICOLA & 430 & 23.8 \\
2 & EBSCO - ASP & 383 & 21.2 \\
3 & EBSCO - ERIC & 268 & 14.9 \\
4 & SABINET - ISAP & 179 & 10.0 \\
5 & SABINET - CCR & 232 & 12.9 \\
6 & EBSCO - MFP & 157 & 8.7 \\
7 & MEDLINE & 103 & 5.7 \\
8 & EBSCO - BSP & 56 & 3.1 \\
& TOTAL & $\mathbf{1 8 0 8}$ & $\mathbf{1 0 0}$ \\
\hline
\end{tabular}

It was surprising to note that MEDLINE ranked number seven, despite the common belief that medicine and health are among the fields that are rich in indigenous knowledge. For instance, the Ghanaian mass media reported a strong message from Agya Kwaku Appiah, President of the Ghana Federation of Traditional Medicine Practitioners Association (GHAFTRAM) in favor of tapping indigenous knowledge in medicine. Appiah is quoted to have said that "we need the assistance of orthodox practitioners, research scientists and the Ministry of Health $(\mathrm{MOH})$ to unearth the wealth of indigenous knowledge in medicine" (see http://www.ghanaweb.com/GhanaHomePage/NewsArchive/artikel.php?ID=89255). The low yield by the MEDLINE database can, however, be attributed to terms or phrases used to download IK data from the databases. The Medical Subject Headings (MESH) thesaurus that is used to index MEDLINE records does not have "traditional knowledge" and "indigenous knowledge" as indexing terms. Instead, the thesaurus uses "Medicine, Traditional" and "Health services, Indigenous" to index indigenous knowledge-related records. When these terms were applied to search for records in MEDLINE, the situation changed and MEDLINE jumped from position seven to position one as shown in Table2.

Table 2 Distribution of IK Records by Database and Year of Publication - using search terms "Medicine, Traditional" and "Health Services, Indigenous" in MEDLINE database

\begin{tabular}{|c|c|c|c|}
\hline Number & Database & Total & Percentage \\
\hline I & MEDLINE & 2806 & 86.18 \\
\hline 2 & EBSCO - ASP & 127 & 3.90 \\
\hline 3 & EBSCO - ERIC & 89 & 2.73 \\
\hline 4 & SABINET - ISAP & 82 & 2.52 \\
\hline 5 & SABINET - CCR & 80 & 2.46 \\
\hline 6 & EBSCO - MFP & 50 & 1.54 \\
\hline \multirow[t]{2}{*}{7} & EBSCO -BSP & 22 & 0.68 \\
\hline & TOTAL & 3256 & 100 \\
\hline
\end{tabular}


4.2 Distribution of documents by document type

There were 1805 documents that provided details on 'document types'. Articles (I279 or $70.9 \%$ ) were dominant IK records in the databases. These included Current and Completed Research database that indexes only completed and current research for degree qualification (e.g. Masters and Doctoral) and non-qualifications. Other documents included abstracts, editorial, interviews and collected works. Evidently, as highlighted on Table 3, non-journal sources are still least indexed by the databases except when a dedicated database for their representation exists such as C\&CR that is an extremely useful database.

Table 3 Distribution by document type $(n=1805)$

\begin{tabular}{|c|c|c|c|c|c|c|c|c|}
\hline Database & Journal Articles & Book Reviews & Editorial & Theses \& Dissert & Collected Works & Research Reports & Others & TOTAL \\
\hline AGRICOLA & 365 & 58 & - & 2 & - & - & 5 & 430 \\
\hline ASP & 337 & 34 & 6 & - & - & - & 6 & 383 \\
\hline ERIC & 134 & 32 & I & - & 29 & 32 & 46 & 274 \\
\hline ISAP & 169 & 10 & - & - & - & - & - & 179 \\
\hline$C \& C R$ & 10 & - & - & 183 & - & 35 & 4 & 232 \\
\hline MEDLINE & 79 & 5 & 4 & - & - & - & 15 & 103 \\
\hline MFP & 141 & 10 & 3 & - & - & - & 3 & 157 \\
\hline BSP & 44 & 1 & 1 & - & - & - & 1 & 47 \\
\hline Total & 1279 & 150 & 15 & 185 & 28 & 67 & 80 & 1805 \\
\hline
\end{tabular}

4.3 Distribution of IK records by database and year of publication

Six databases from EBSCO Host, namely Academic Search Premier (ASP), AGRICOLA, Business Source Premier (BSP), Master File Premier (MFP), ERIC, and MEDLINE as well as two databases from SABINET, ISAP and C\&CR that produced 1808 records were accessed for records on indigenous knowledge. Table 4 shows the distribution of documents, including duplicates, by database and year of publication, except for 53 records that did not provide year of publication information. The results show an increase of IK research from 1996 in general terms.

Table 4 Distribution by database and year of publication/completion $(\mathrm{N}=1755)$

\begin{tabular}{|c|c|c|c|c|c|c|c|c|c|c|c|c|c|c|c|c|}
\hline DATABASE & 1990 & 1991 & 1992 & 1993 & 1994 & 1995 & 1996 & 1997 & 1998 & 1999 & 2000 & 2001 & 2002 & 2003 & 2004 & TOTAL \\
\hline AGRICOLA & 23 & 41 & 28 & 26 & 11 & 9 & 30 & 26 & 16 & 29 & 26 & 37 & 57 & 25 & 45 & 429 \\
\hline EBSCO - ASP & 0 & 3 & 3 & 5 & 4 & 5 & 14 & 20 & 15 & 25 & 33 & 45 & 60 & 81 & 70 & 383 \\
\hline EBSCO - ERIC & 2 & 5 & 7 & 8 & 7 & 7 & 22 & 21 & 36 & 25 & 45 & 36 & 29 & 18 & 0 & 268 \\
\hline SABINET - ISAP & 1 & 1 & 6 & 4 & 4 & , & 6 & 9 & 13 & 14 & 24 & 20 & 30 & 27 & 13 & 179 \\
\hline SABINET - CCR & 5 & 8 & 9 & 13 & 12 & 17 & 20 & 17 & 11 & 26 & 23 & 9 & 5 & 5 & 0 & 180 \\
\hline MEDLINE & I & 2 & 3 & 6 & 0 & 5 & 3 & 6 & 4 & 7 & 12 & 8 & 10 & 16 & 20 & 103 \\
\hline EBSCO - MFP & 0 & 2 & 2 & 3 & 4 & 4 & 7 & 9 & 7 & 9 & 20 & 16 & 24 & 31 & 19 & 157 \\
\hline EBSCO -BSP & 0 & 0 & 0 & I & 2 & 0 & 2 & 4 & 0 & I & 4 & 9 & II & 11 & 11 & 56 \\
\hline TOTAL & 32 & 62 & 58 & 66 & 44 & 54 & 104 & 112 & 102 & 136 & 187 & 180 & 226 & 214 & 178 & 1755 \\
\hline
\end{tabular}

4.4 Growth of indigenous knowledge literature from 1990-2004

The number of documents published over the duration of time is useful for trend analysis and may also be valuable for forecasting strategies to be undertaken for development. For instance, in measuring growth in IK literature, Fig. 3 below demonstrates the trend of literature on indigenous knowledge from 1990 to 2002 . Generally, there has been a remarkable rise in the number of IK documents overall from 1997. Speculatively, the rise could be attributed to the increased attention to knowledge management and the recognition of IK in the knowledge domain. Second, it could be the improvement on resource support to IK research and popularization particularly due to IK impact on, for example, health and nutrition in areas such as in sports and alternative medicine as well as in the informal sector/industry. The desire of indigenous communities, which increasingly hold strategic civil and policy making positions either nationally or internationally, to preserve their heritage and the opportunities and threats created by globalization, has increased the need for capturing, recording, storing and disseminating IK. We believe that there is a remarkable sensitivity and development of IK in South Africa as attested by the existence of policies and structures by/in the government of South Africa (e.g. at the Department of Arts, Culture and Technology and the National Research Foundation -NRF). The Library and Information Association of South Africa (LIASA) and SCECSAL have also given IK some focus (http:// www.dissanet.com). Analysis of the records by databases in Fig. 4 display negative growth in current and completed research in 2004. The negative growth could be attributed to gradual indexing that goes into the following year. 


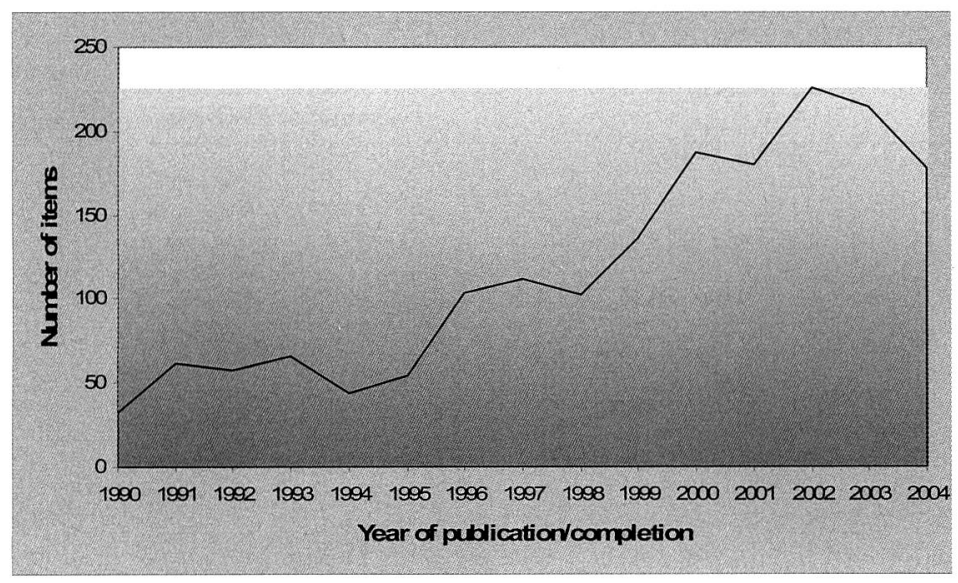

Figure 3 Growth of IK Literature, 1990-2004

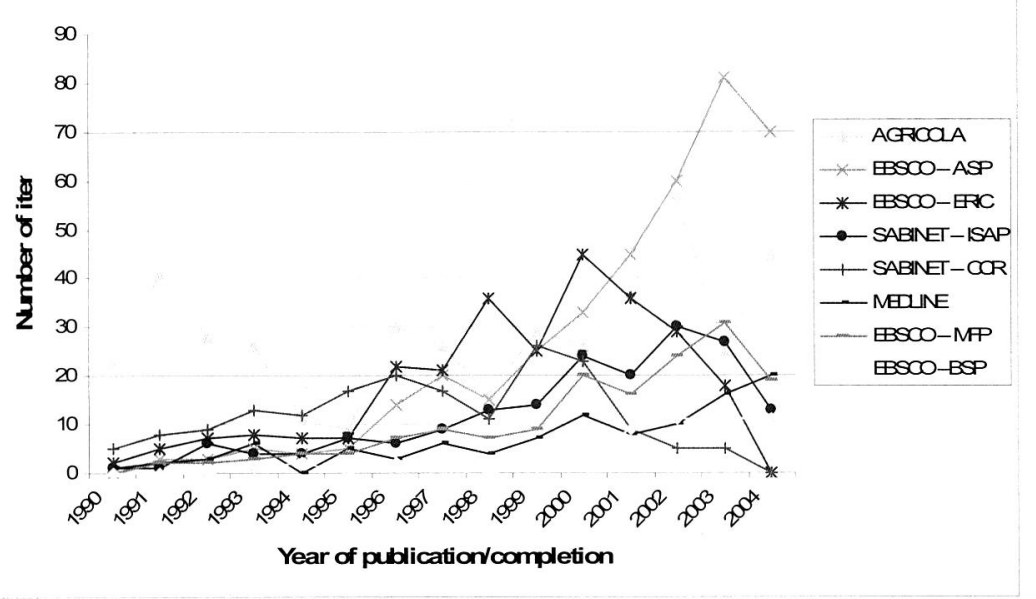

Figure 4 Growth of IK Literature by database, 1990 to 2004

\subsection{Distribution of documents by source}

Source refers to records in which the IK has been captured or represented. Journals are still dominant sources of scholarly literature and for the determination or measurement of research output of, for example, a country, organization or individual. The intent of this analysis is to determine the scope and number of journals that publish IK documents and to determine whether there are core journals in IK. The supplementary intention is to determine the contribution of South African journals to this pool of knowledge. A total of 458 sources (i.e. journals, newsletters, magazines, etc.) from seven databases (ASP, AGRICOLA, BSP, MFP, ERIC, MEDLINE and ISAP) represented articles on Indigenous Knowledge. Current and Completed Research(C\&CR) database does not comprise journal sources, therefore, was excluded for analysis. Table 5 compares the overall performance of the sources indexed in these databases that produced 4 and more publications each within the period of study.

The use of ISAP database in this analysis has given South African Journals (italicized in Table 5) visibility and advantage over the foreign journals. The results obtained have also demonstrated the usefulness of databases reflecting on national/ local output for informetric research. Most South African journals indexed in ISAP are not indexed in the four EBSCO databases. Despite the naming of some journals with the word indigenous, their results in this analysis show that there is no core IK journal. It was, however, expected that some journals would emerge as core IK journals. Strangely, none of the knowledge management journals featured articles on IK even though IK is increasingly represented in tangible/explicit knowledge. 
Table 5 Sources of IK Publications

\begin{tabular}{|c|c|}
\hline Source & Number of Records \\
\hline Winds of Change & 22 \\
\hline Journal of Ethnopharmacology & 21 \\
\hline Nature & 13 \\
\hline South African Journal of Education & 11 \\
\hline International Social Science Journal & 11 \\
\hline Canadian Journal of Native Education & 11 \\
\hline Managing Intellectual Property & 10 \\
\hline Human Ecology: An Interdisciplinary Journal & 9 \\
\hline South African Journal of Library and Information Science & 8 \\
\hline Review of European Community and International Environmental Law & 8 \\
\hline Geoderma & 8 \\
\hline Australian Journal of Indigenous Education & 8 \\
\hline New Scientist & 7 \\
\hline Native Americas & 7 \\
\hline International Journal for Sustainable Development and World Ecology & 7 \\
\hline Farmer's weekly & 7 \\
\hline American Indian Culture and Research Journal & 7 \\
\hline World Archaeology & 6 \\
\hline UNESCO Sources & 6 \\
\hline Tribal College & 6 \\
\hline South African Journal of Higher Education & 6 \\
\hline Sharing our Pathways & 6 \\
\hline Saskatchewan Sage & 6 \\
\hline Pharmaceutical Biology & 6 \\
\hline Lancet (Elsevier) & 6 \\
\hline International Review of Education & 6 \\
\hline Third World Quarterly & 5 \\
\hline Society and Natural Resources & 5 \\
\hline Science Education & 5 \\
\hline Northern Review & 5 \\
\hline Journal of American Indian Education & 5 \\
\hline Environmental monitoring and assessment & 5 \\
\hline Comparative Education & 5 \\
\hline Anthropology Today & 5 \\
\hline Africa Today & 5 \\
\hline Wicaso SA Review & 4 \\
\hline South African journal of science & 4 \\
\hline Osiris & 4 \\
\hline Journal of Navajo Education & 4 \\
\hline Ambio & 4 \\
\hline Alberta Report / Newsmagazine & 4 \\
\hline African Wildlife & 4 \\
\hline Africa insight & 4 \\
\hline
\end{tabular}

4.6 Distribution of IK publications by document affiliation

Affiliation here is two-fold. In the first instance it refers to the geographical or place link of the document or "aboutness" of the document based on the analysis of ASP, MFP, BSP, ERIC, MEDLINE and ISAP. The second set provides institutional affiliation of the research report in South Africa as reflected in C\&CR database. The information in Table 6(a) is essential 
for determining the concentration and scatter of IK research and publication, why this is the case and the gaps for attention through, for example, resource support..

Table 6(a) Affiliation by Geographical Coverage of IK Documents

\begin{tabular}{|c|c|c|c|c|c|c|c|c|c|}
\hline Rank & Country & ASP & BSP & ERIC & MFP & AGRICOLA & MEDLINE & ISAP & TOTAL \\
\hline $\mathrm{I}$ & United States & 10 & 3 & 19 & 15 & 15 & 23 & - & 85 \\
\hline 2 & Canada & 20 & 3 & 21 & 25 & 8 & 5 & - & 82 \\
\hline 3 & South Africa & 11 & 2 & - & 3 & - & I & 42 & 59 \\
\hline 4 & Africa & 12 & 1 & 6 & 5 & 2 & 6 & 19 & 51 \\
\hline 5 & Alaska & 2 & 2 & 41 & 2 & - & - & - & 47 \\
\hline 6 & Developing Countries & 6 & 3 & 4 & 4 & 4 & 15 & 4 & 40 \\
\hline 7 & India & 19 & - & 4 & 8 & 3 & 4 & - & 38 \\
\hline 8 & Australia & 10 & 1 & 13 & 4 & 1 & 1 & - & 30 \\
\hline 9 & Mexico & 7 & 1 & I & 1 & 8 & 3 & - & 21 \\
\hline 10 & Arctic Regions & 1 & - & 11 & - & - & 3 & - & 15 \\
\hline 11 & Brazil & 6 & - & - & 2 & 1 & 5 & - & 14 \\
\hline 12 & Asia & 3 & & 4 & & 1 & 6 & - & 14 \\
\hline 13 & China & 6 & 1 & - & 1 & 3 & - & - & 11 \\
\hline 14 & Alberta & 2 & 1 & 1 & 4 & 2 & - & - & 10 \\
\hline 15 & Thailand & 4 & - & - & 4 & - & 1 & - & 9 \\
\hline 15 & Italy & 1 & - & - & - & 5 & 3 & - & 9 \\
\hline 15 & Great Britain (UK) & 2 & - & 2 & 1 & 3 & - & 1 & 9 \\
\hline 16 & Nigeria & 1 & - & - & - & 2 & 3 & 1 & 7 \\
\hline 16 & Nepal & 1 & - & - & 1 & 4 & 1 & - & 7 \\
\hline 16 & Morocco & I & - & - & 1 & 4 & 1 & - & 7 \\
\hline 16 & Kenya & 6 & - & - & - & 1 & - & - & 7 \\
\hline 16 & Germany & 1 & 1 & 1 & 1 & 2 & 1 & - & 7 \\
\hline 16 & California & 1 & - & 1 & - & 4 & 1 & - & 7 \\
\hline 16 & Amazon River Region & 3 & - & 1 & 1 & 2 & - & - & 7 \\
\hline 17 & Africa, West & 2 & - & 1 & 1 & - & 1 & 2 & 7 \\
\hline 17 & Saskatchewan & - & 1 & - & 5 & - & - & - & 6 \\
\hline 17 & Philippines & 3 & - & - & - & 2 & 1 & - & 6 \\
\hline 17 & Peru & 2 & 1 & - & - & 2 & 1 & - & 6 \\
\hline 17 & France & 3 & - & - & 1 & 2 & - & - & 6 \\
\hline 18 & Zimbabwe & 2 & - & 1 & - & I & - & 1 & 5 \\
\hline 18 & Uganda & 3 & - & - & - & 1 & 1 & - & 5 \\
\hline 18 & Senegal & 2 & - & - & 2 & 1 & - & - & 5 \\
\hline 18 & Pacific & 3 & - & - & I & - & 1 & - & 5 \\
\hline 18 & New Zealand & 2 & - & 2 & - & - & 1 & - & 5 \\
\hline 18 & Malaysia & 3 & - & - & 2 & - & - & - & 5 \\
\hline 18 & Latin America & - & - & 2 & - & 1 & 2 & - & 5 \\
\hline 18 & Ethiopia & 1 & - & 1 & - & 3 & - & - & 5 \\
\hline 18 & Colombia & 2 & - & - & - & 1 & 2 & - & 5 \\
\hline 18 & British Columbia & 1 & 1 & 1 & 1 & - & 1 & - & 5 \\
\hline 18 & Africa, Southern & 1 & - & - & 1 & - & 1 & 2 & 5 \\
\hline
\end{tabular}

Table 6(b) reflects on IK research affiliation in South Africa largely with similar intentions as in Table 6(a). Similarly, nformation reflected on the latter provides familiarity with areas of IK research and affiliation that is largely essential for research collaboration generally and in South Africa in particular. Whereas IK development and support in South Africa seem to be increasing in this representation, it should, however, be noted that South Africa feature more frequently in this analysis because of using ISAP and C\&CR databases that covers the country only. Table 6(a) provides a list of the countries in the first category. Evidently, there is concentration of IK research and publication on Africa and on the indigenous communities in the US and Canada. Apart from the US, South Africa and India, country link with the documents is insignificant. It is probable that more information could be gained through non-journal sources or through national bibliographies. It could also be that IK is not supported. Regarding South African C\&CR representation by institutional affiliation as reflected in Table 6(b), the distribution seems to scatter widely among the Universities in the country.i 
Table 6(b) South African Institutional Affiliation of C\&CR

\begin{tabular}{|c|c|c|}
\hline Institute & Number of records & Percentage \\
\hline University of Pretoria & 37 & 16 \\
\hline University of Stellenbosch & 24 & 10.4 \\
\hline University of Natal (PMB) & 19 & 8.2 \\
\hline Rand Afrikaans University & 17 & 7.4 \\
\hline University of Cape Town & 16 & 6.9 \\
\hline University of The Witwatersrand & 16 & 6.9 \\
\hline University of South Africa & 15 & 6.5 \\
\hline Rhodes University & 14 & 6.1 \\
\hline Potchefstroom University for $\mathrm{CHE}$ & 9 & 3.9 \\
\hline University of Zululand & 7 & 3.1 \\
\hline Milpark Business School & 6 & 2.6 \\
\hline University of Durban-Westville & 6 & 2.6 \\
\hline University of the Orange Free State & 6 & 2.6 \\
\hline Human Sciences Research Council & 4 & 1.8 \\
\hline University of Port Elizabeth & 4 & 1.8 \\
\hline University of The North-West & 4 & 1.8 \\
\hline University of Venda & 4 & 1.8 \\
\hline Vista University & 4 & 1.8 \\
\hline University of the Western Cape & 3 & 1.3 \\
\hline CSIR & 2 & 0.9 \\
\hline University of Fort Hare & 2 & 0.9 \\
\hline University of The Free State & 2 & 0.9 \\
\hline University of The North & 2 & 0.9 \\
\hline Cape Technikon & 1 & 0.5 \\
\hline Durban Institute of Technology & 1 & 0.5 \\
\hline Foreign University & 1 & 0.5 \\
\hline Technikon Natal & 1 & 0.5 \\
\hline Technikon Pretoria & 1 & 0.5 \\
\hline Transvaal Museum (Pretoria) & I & 0.5 \\
\hline Tshwane University of Technology & 1 & 0.5 \\
\hline University of Transkei & 1 & 0.5 \\
\hline Vaal Triangle Technikon & 1 & 0.5 \\
\hline TOTAL & 232 & 100 \\
\hline
\end{tabular}

4.7 Subject representation of IK literature.

Subject identifiers and descriptors from the documents in the eight databases were captured and stored in the Excel spreadsheet and sorted out to select the documents' main subject coverage and their sub-divisions as displayed in Table 7. It was noted that subject coverage is generally broad. The community or people identifier with the documents tend to, largely, stereotype IK with particular indigenous communities whose cultures were strongly affected by the occupation of their territories by foreigners. This stereotype that has identified indigenous knowledge with inferiority and backwardness, in our view, has tremendously affected IK development until recently, when the impact (e.g. alternative medicine, pharmaceutical industries, and healing, intellectual property issues) and disappearance of the knowledge was acknowledged. Table 7 only gives the broad areas of the subject domain, including some qualifiers. . 
Table 7 Subject Scope of IK

\begin{tabular}{ll}
\hline \multicolumn{1}{c}{ Subject Scope/Discipline } & \multicolumn{1}{c}{ Subject sub-division } \\
\hline Agriculture & Crops; Animals; Ecosystem; Extension; Pastures; Fisheries \\
Anthropology & Ethno science; Anthropocentrism; Ethnography \\
Archeology & Buildings \\
Biodiversity & Droughts; Ecology; Nature; Environmental Sciences; Biological diversity \\
Cultural dimension & Ceremonies; Communication; Customary law; folklore; Healing; Language; Religion; Traditions; Cultural differences \\
Education & Adult education; Adult basic education; Educational strategies, theories, research, philosophy and development; \\
Environment & Awareness; Conservation; Degradation; Education; Science \\
Food & Supply, Security, resources, processing, and storage \\
Health \& Medicine & Alternative medicine; Herbs; HIV; AIDS; Sport; Traditional medicine; Medicinal plants; Health planning and \\
Information Science & Knowledge management; Access to information; \\
Law & Customary law; Intellectual property; Patent \\
Local knowledge & Environmental protection; Health promotion; Nutrition; Pharmacology \\
People & Aboriginal people; American Indians; Australian Aborigines; Aztec people; Cree Indians; Eskimo; Luo; Maori; Native \\
Psychology & Healing; Religion; Sangomas \\
Sociology & \\
Sustainable development &
\end{tabular}

4.8 Nature of Authorship

Research collaboration is normally measured by co-authorships. Laudel (200I) provides an insightful reflection on measurement of co-authorship that is becoming increasingly essential for collaborative research and research partnership. An analysis of the IK publications or literature was also done by nature of authorship, whether documents were single authored or jointly authored. Single authored publications totaled 859 (58\%) as opposed to the co-authored (623 or 42\%) as shown in Table 8. The C\&CR documents (232) were not included for the analysis because theses and dissertations are single authored and therefore could create a biased representation.

Table 8 Distribution by nature of authorship and database

\begin{tabular}{clccc}
\hline Rank & \multicolumn{1}{c}{ Database } & Single-authorship & Co-authorship & TOTAL \\
\hline I & AGRICOLA & 169 & 290 & 429 \\
2 & EBSCO - ASP & 241 & 121 & 362 \\
3 & EBSCO - ERIC & 158 & 92 & 250 \\
4 & EBSCO - MFP & 118 & 27 & 145 \\
5 & SABINET - ISAP & 97 & 47 & 144 \\
6 & MEDLINE & 40 & 61 & 101 \\
7 & EBSCO - BSP & 36 & 15 & 51 \\
& TOTAL & $\mathbf{8 5 9}$ & $\mathbf{6 2 3}$ & $\mathbf{1 4 8 2}$ \\
\hline
\end{tabular}

\section{Conclusions}

The study reveals that most IK is published in journals. AGRICOLA, ASP, ERIC and C\&CR databases represent most IK documents. However, MEDLINE would yield most records if the search phrases "traditional medicine" and "indigenous health services" were used as shown in Table 2. The growth of IK documents has significantly increased from 1997 2002. This may suggest that there is increasing interest and support to IK. The increase of publications over time (I5 years) is spread among the databases. There is no core IK journal. Single authors produce over $58 \%$ of the IK documents. IK research and link by country, apart from US, India, South Africa (features strongly because of using SABINET hosted C\&CR and ISAP) and Mexico, is insignificant. There is a diversified scatter of IK research affiliation at the Universities in South Africa. Most of these results (e.g. publication in periodicals as opposed to other publications and publication by single authors as opposed to joint authors) concur with Onyancha and Ocholla's study (2004) on corruption literature in Africa between 1990-200I that covered 474 documents published within that period using EBSCO-hosted ASP and MFP. The subject scope of $I \mathrm{~K}$ research is diversified and multidisciplinary in scope and orientation. There is a strong reflection of IK in agricultural literature that suggests increased recognition of IK for agricultural purposes. It is concluded that IK is an important part of knowledge management that should receive great attention as it provides recognizable support to tangible/modern knowledge/intellectual capital. Unfortunately, IK has been marginalized and insufficiently tapped for human exploitation. It is possible to extend our minds on the following:

- Creation of IK database (for S. Africa and Africa e.g. Completed and Current IK Research on Africa). The identification and indexing of local /African periodicals with IK is also essential. We have noted that most IK could be indexed or captured from local sources (e.g. C\&CR and ISAP) other than international databases/database hosts that capture major (e.g. ISI and EBSCO) information sources only. We also feel that indexing of C\&CR in a country (e.g. South 
Africa) has to be thorough and properly edited in order to provide accurate records and reflection.

- Creation and Development of IK Journal such as INDILINGA

- IK research support (strong structures for the purpose (legislation, government departments, National Research Foundation etc) already exist in South Africa but more can still be done.

- Popularization of IK, for instance in schools and in the curriculum of education institutions

- Further policy and structural development for IK sustainability

- Integration of IK within KM. This is still weak

- Creation of an IK website for its publicity and promotion. There are some sites (see. Le Roux 2003) though on which to build linkages.

Further research will include an exploitation of other bibliometric methods (e.g. co-word analysis, citation analysis and the impact factor analysis of 'knowledge management' research).

\section{Acknowledgements}

Versions of this paper were presented at the International Conference on Collaboration and Sharing of Knowledge, 30 \& 31 July 2003. Unisa (SA) Pretoria and the 10th International Conference of the International Society for Scientometrics and Informetrics, Stockholm, July 24-28, 2005. We wish, particularly, to acknowledge the reviews of the full text of this paper for ISSI conference and the University of Zululand for partially funding our participation at the ISSI conference.

\section{References}

Archambault, E. \& Gagne, E.V. (2004). The use of bibliometrics in the social sciences and humanities: a report prepared for the Social Sciences and Humanities Research Council of Canada (SSHRCC). Quebec, Canada: SSHRCC.

Björneborn, L. \& Ingwersen, P. (2004). Towards a basic framework of webometrics, Journal of the American Society for Information Science and Technology, 55(14): 1216-1227

Diodato, V. (1994). Dictionary of Bibliometrics. New York: Haworth.

Hertzel, D (1987) Bibliometrics, History of the Development of Ideas in Statistical Bibliography or Bibliometrics? In: Kent, A \& Lancour H., and editors. Encyclopedia of Library and Information Science, vol.42: 144-2 I9 Hood, W.W. \& Wilson,C.S. (200I). The literature of bibliometrics, scientometrics and informetrics. Scientometrics, 52(2):29I-
314 .

Ikpaahindi, L. (1985) An Overview of Bibliometrics: its Measurement, Laws and Their Application. LIBRI, 35(2):163-177

Laudel, G. (200I). What Do We Measure by Co-authorship? In M. Davis \& and C.S. Wilson (eds.). The $8^{\text {th }}$ International Conference on Scientometrics and Informetrics Proceedings - ISSI-200I vol. I.pp.369-384

Lewison, G. (2002). From biomedical research to health improvement. Scientometrics, 54(2): 1 79- 192.

Marshakova I. (1 973). System of Docummentation Connections based on References (SCI). Nauchno-Techn. Inform. 2(6): 3-8

Mosia, L.N. \& Ngulube, P. (2005). Managing the collective intelligence of local communities for sustainable utilization of estuaries in the Eastern Cape. South African Journal of Libraries and Information Science, 7I (2): 175- 186

National Research Foundation (NRF). (2003). Indigenous knowledge systems. [Online] Available: http://www.nrf.ac.za/ focusareas/iks/. Acessed 10 November 2003

Nonaka, I. \& Takeuchi, H. (1995). The knowledge-creating company: how Japanese companies create the dynamics of innovation. New York: Oxford University Press.

Ocholla, D.N. (2000). Research capacity in library and information science in South Africa: an overview. Proceedings of the $66^{\text {th }}$ IFLA Council and General Conference, Jerusalem, Israel, I3-I8 August 2000. [Online] Available: http://www.ifla.org/iv/ifla66/
papers/054- / 27e.htm. Accessed I 7 July 2004

Onyancha, O.B. \& Ocholla, D.N. (2004) An informetric analysis of the corruption literature based on Africa between 1990 and 200 I. South African Journal of Libraries and Information Science, 70(2):86-98

Pichappan, P. \& Sarasvady. S. (2002). The other side of the coin: the intricacies of author self-citations. Scientometrics, 54(2):285290

Polanco, X. (1995). With the Sources of Scientometry (A translation of Aux sources de la scientometrie). [Online]Available: http://www.info.unicaen.fr/bnum/jelec/Solaris/d02/2polanco.html. Accssed 19 March 2002 Rousseau, R. (2002) Timeline of Bibliometrics. [Online] Available: http://users.pandora.be/ronald.rousseau/html/timeline of
bibliometrics.html. Accessed: 20 March 2002 . Le Roux, C.J.B. (2003). Tapping indigenous knowledge on the WWW. Indilinga: African Journal of Indigenous Knowledge Systems,
2(I):107-I I3

Sengupta, I.N. (1992). Bibliometrics, Informetrics, Scientometrics and Librametrics: an Overview. Libri, 42(2):75-98 Small H. (1 973). Co-citation in the Scientific Literature: A New Measure of the relationship between two documents. American
Society for Information Science, 24

Twining, J. (200I). Bibliometrics - an overview. [Online] Available: http://www.du.edu/-jtwining/LIS4326/bibliometrics.htm. Accessed I July 2003

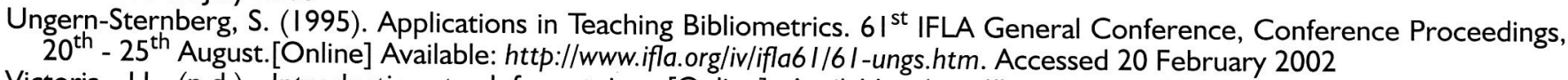

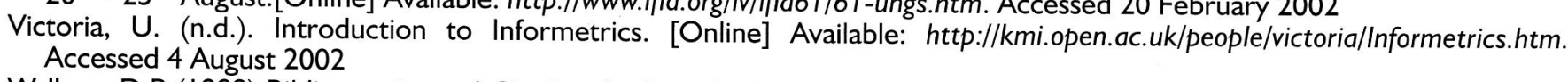

Wallace, D.P. (1989) Bibliometrics and Citation Analysis. In: J.N. Olsgaard (ed.). Principles and Applications of Information Science for library Professionals. Chicago; ALA, p. 10-26

Wormell, L. (200I). Informetrics for Informed Decision Making: Seminar Paper. Swedish-Lithuanian Seminar on Information Management Research Issues held on 2I-22, Sept. 200I, at the University College of Boras, Sweden. [Online] Available: http://www.hb.se/bhs/seminar/semdoc/wormell.htm. Accessed 19 February 2002. 